\title{
Essential Latex Processing Plant (ELPP): A Pioneer Approach in the Production of Concentrate Latex from Local Resource to Manufacture Male Contraceptive in Bangladesh
}

\author{
Sadia Afreen ${ }^{1}$, Kh. Rashedul Haque ${ }^{2}$, Md. Shariful Islam ${ }^{3}$, Dr M Kadrul Huda ${ }^{4}$ \\ ${ }^{1}$ Engineering Officer (Chemical), Dhaka Plant, EDCL; Project Member(ELPP), Email: sadiafreen002@gmail.com \\ ${ }^{2}$ DM, Quality Assurance, Dhaka Plant, EDCL; Project Manager (ELPP) \\ ${ }^{3}$ Quality Control Officer, Dhaka Plant, EDCL; Project Member (ELPP) \\ ${ }^{4}$ Managing Director, EDCL; Project Director (ELPP)
}

\begin{abstract}
For years, a respective amount of PV latex has been exported from Malaysia to manufacture male contraceptives within the country. Recently, a project titled as ELPP, has been undertaken by the Govt. Pharmaceutical Company 'Essential Drugs Company Ltd' to pioneer the implementation of processing natural raw latex (35-40\% dry rubber content) [1] into concentrate latex (60\% dry rubber content) [1] from the local resource at Modhupur region. The purpose of this project is to produce concentrate latex from local resource as the raw material for manufacturing male contraceptive instead of importing the latex from Malaysia or other countries. Several trials have been taken place to test the feasibility and productivity of the project with respect to the aspects in Bangladesh. The results and observations are found very satisfactory and the project is very much cost effective since it cuts off the foreign expense caused due to the import of concentrate latex from abroad at present days. An overall cost analysis shows that if the technology of processing concentrate latex is implemented with a proper utilization of the local resources it reduces the cost of production to a great extent. Moreover, rubber sheets produced as the byproduct from this process are very much useful and demandable in the field of rubber industries and add profit to the process.
\end{abstract}

\section{INTRODUCTION}

Bangladesh has a good prospect in the field of rubber manufacturing industries since there are substantial local resources here to provide the raw materials for manufacturing rubber goods and concentrate latex. At present, there are total fifteen rubber gardens situated at Modhupur, Sylhet and Chittagong regions in Bangladesh [2]. The rubber trees, scientific name Hevea brasiliensis, found in these areas are very potential resource of natural latex for producing commercial rubber and latex concentrate. Latex concentrate is used as the raw material for manufacturing male contraceptives, hand gloves and similar thin walled articles. To manufacture these products concentrate PV latex are imported from foreign resources in our country. At the Khulna Essential Latex Plant, male contraceptives are being manufactured with this imported concentrate latex. The current project, titled as Essential Latex Processing Plant (ELPP), is a pioneer in this field which is going to use the local resource for this purpose instead of buying the raw material from foreign resources in purpose of manufacturing condom. The current project is based on the local resource at Madhupur rubber garden from which natural raw latex is collected to make it into concentrate which is the main raw material for manufacturing male contraceptive at Khulna Essential Latex Plant. A detail cost analysis has been done to check the feasibility of the process before the implementation for commercial purpose.

\section{OBJECTIVE OF THE PROCESS}

- To obtain $60 \%$ of dry rubber content from $25-30 \%$ of rubber hydrocarbon as the main product.

- Use the product as the raw material in manufacturing male contraceptive.

- To produce rubber sheets as the byproduct of the process.

- To cut off the foreign expense to import conc. PV latex.

\section{THE AVERAGE COMPOSITION OF NATURAL LATEX}

Table 1. Composition of Natural Raw Latex [1], [3]

\begin{tabular}{|l|c|}
\hline \multicolumn{1}{|c|}{ Content } & Percentage \% \\
\hline Water & 60 \\
\hline Rubber Hydrocarbon & $25-35$ \\
\hline $\begin{array}{l}\text { Proteins, Enzymes and } \\
\text { Nucleic Acids }\end{array}$ & 3 \\
\hline Fatty Acids and Esters & 1 \\
\hline Inorganic Salts & 0.5 \\
\hline
\end{tabular}




\section{PROCESS DESCRIPTION}

For the purpose of processing concentrate latex, natural raw latex is collected from the rubber trees found in the rubber garden at Modhupur. This raw latex contains 35$40 \%$ dry rubber content [3]. Tapping is recommended to start at the very early morning to get the fresh latex. Latex collection from the field is a very sensitive part of the total process because latex can easily get contaminated by the microorganisms and bacteria present in the surrounding environment. Care should be taken during tapping that no insects, leaves, dirt or bacterial attack may take place in the collected latex. Also proper cautions are required for the collection pots, vessels and drums; these should be neat and clean to avoid any bacterial or microorganism attack into the latex. However, in spite of all the cautions latex may get tainted somehow at any stage of the whole process. Raw latex is very sensitive that a slight or nominal contamination can easily progress into coagulation which will bring loss to the process because coagulated latex can not be processed into concentrate which is the desired product. For this reason during the collection of raw latex from the field ammonia and other anticoagulant agents are added into it. After collecting the field latex it is transferred into reception tanks where again some anticoagulant and stabilizing agents are added to maintain the desired latex property before it goes to centrifuge. After settling the raw latex from 12-24 hours in the reception tanks, the latex is centrifuged at 1400 RPM, which separates it into two parts; one is Latex Concentrate $(60 \%)$ and the other is Skim [3]. The concentrate latex is then shifted into the storage tank where it is kept for 21 days for maturation. Before the storage again some anticoagulant agents and stabilizing chemicals are added so that the properties of the final product in the storage tank do not go under any deterioration. The other part, skim is sent to the deammoniation tower to remove the ammonia before it goes to creping to form rubber sheets. The deammoniated skim is then transferred into large tanks for acid treatment; this makes the skim coagulate into rubber blocks. The coagulated rubber blocks are then processed into thin rubber sheets in a creping machine. These rubber sheets are the by product of this process.

\section{PROCESS FLOW DIAGRAM}

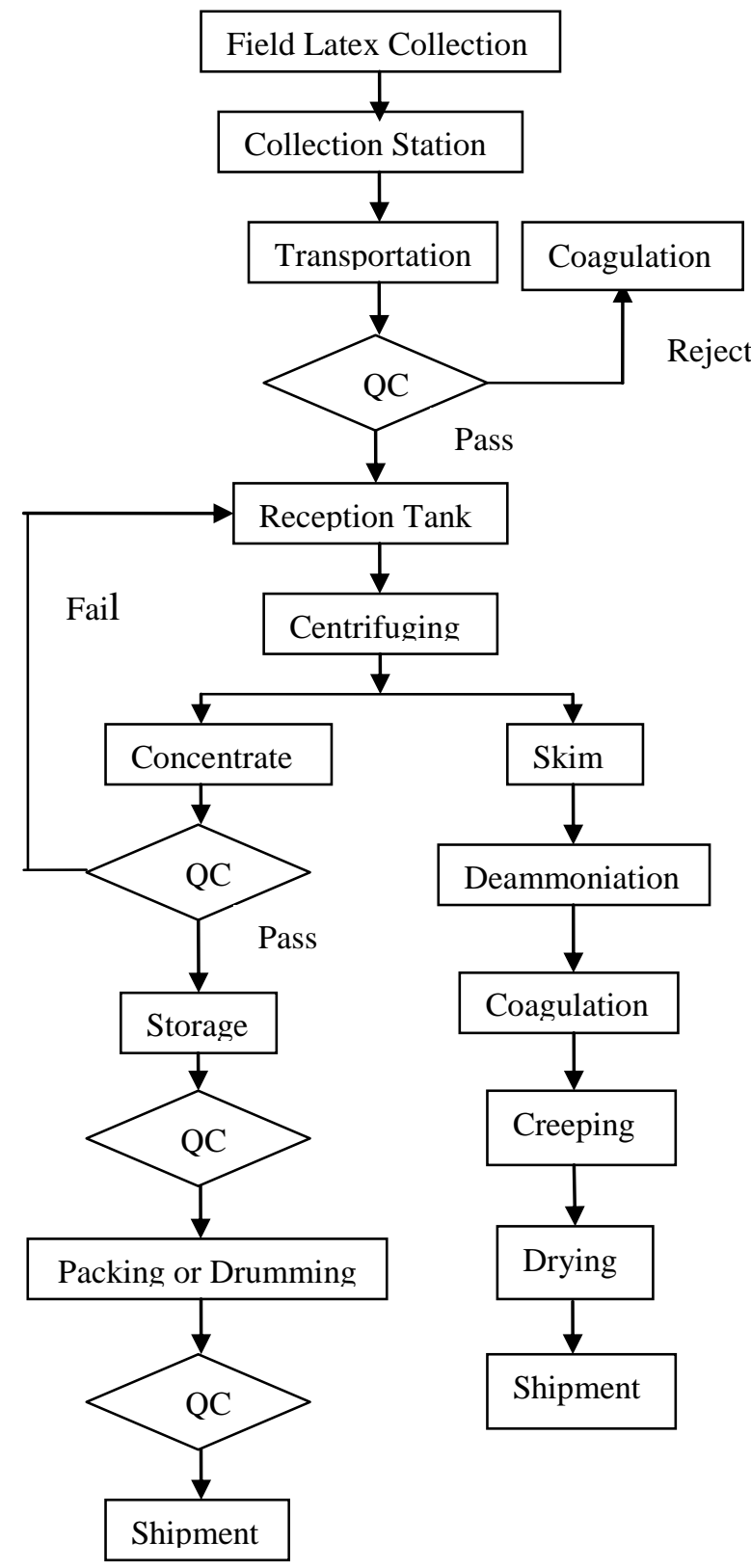

Fig. 1: Process flowchart of latex concentrate 


\section{ESSENTIAL PARAMETERS THAT CONTROL THE QUALITY OF FINAL PRODUCT}

\subsection{Volatile Fatty Acid (VFA)}

The volatile fatty acids in latex are formed by action of microorganisms upon some of the serum carbohydrates. Formic, acetic and propionic acids are present with acetic acid in predominance. The amount of volatile fatty acids in latex is expressed by the volatile acid number (VFA No.) which is the number of grams of potassium hydroxide required to neutralize the volatile fatty acids in a latex sample containing $100 \mathrm{gm}$ of the total solids [3]. VFA is actually the enemy of the final latex product. It should be not more than 0.06 in the raw latex, and must be less than 0.03 in the final product [3]. VFA is required to be checked frequently during the process operation; the high value of VFA means the quality of latex is poor to be processed further or it is out of order for manufacturing next product from it.

\subsection{Ammonia}

Determination of ammonia content in the final product is necessary, since presence of sufficient ammonia actually ensures a quarantine environment for the latex to avoid any microorganisms' actions upon the sugar contents of the latex. The desired amount of ammonia in the final product should be minimum $0.60 \%$ [3].

\subsection{MST}

MST or mechanical stability means the stability of the latex concentrate to mechanical shear forces. The value of mechanical stability is low at the day of production but increase steadily within the first four or six months of storage to give values of MST between 500-1500 [3] After twenty one days maturation in the storage tank the MST value should reach at a value minimum 650 [3].

\section{PRODUCT SPECIFICATION}

Table 2. Specifications of final Latex concentrate [3]

\begin{tabular}{|l|c|}
\hline \multicolumn{1}{|c|}{ Characteristics } & Limit \\
\hline Total solids content, \% (min) & 62.5 \\
\hline Dry rubber content, \% (min) & 61.0 \\
\hline Non-rubber content, \% (max) & 2.0 \\
\hline $\begin{array}{l}\text { Volatile fatty acid (VFA) number, \% } \\
\text { (max) }\end{array}$ & 0.03 \\
\hline Mechanical Stability, seconds, (min) & 650 \\
\hline $\mathrm{pH}(\min )$ & 10 \\
\hline Coagulum content, \% (max) & 0.005 \\
\hline Alkalinity (as NH3), \% (min) & 0.65 \\
\hline KOH number, \%, (max) & 1 \\
\hline
\end{tabular}

\section{CONCLUSION}

Natural latex performs a special importance in the rubber industry as it is still being the main raw material for various rubber manufacturing operations. Synthetic latex can also be an alternate to natural latex but still natural latex remains of special interest because natural latex is more durable, resilient, healthier and comfortable for manufacturing contraceptive products [5]. Especially it is wise and cost effective to use the natural latex where local resource is available. For the first time in Bangladesh, the process of obtaining concentrate latex $(60 \%)$ from the natural resource is going to be established by ELPP at Modhupur with a view to using this product for manufacturing latex condom at their Khulna plant as well as creating a local market of concentrate latex throughout the country to reduce the foreign expense currently being observed for buying concentrate latex from foreign resource. Several trials, tests and measures have been taken place to understand the feasibility and for the validation of the process with a view to bringing our country at a significant place in the field of commercial rubber industries eventually. Since this technology is going to be implemented first time in Bangladesh with commercial purpose, it needs more trials and modifications to ensure high product quality and to avoid any process flaw in future. Bangladesh has potential land areas situated in the Chittagong and Sylhet regions, at Gazipur, Comilla, Tangail, Mymenshingh, Jamalpur, and Sherpur in Dhaka division and at Rangpur, Dinajpur, Rajshahi, and Bogra in North Bengal region which have suitable soil and climate condition for flourishing more rubber gardens to meet the local demand of rubber for manufacturing different types of rubber goods [2]. The current project is going to be a groundbreaker in the field of rubber manufacturing industries in Bangladesh, further research and initiatives to utilize the local resources in this field will provide a sufficient supply of latex in future instead of importing it from outside for manufacturing male contraceptive locally as well as different types of rubber goods.

\section{ACKNOWLEDGEMENT}

Special thanks go to the Poly Era Chemicals, Malaysia, for their consultancy and co operation, and for their provided information on latex processing. Also thankful to the management body of the Essential Latex Processing Plant, Khulna Essential Latex Plant and the Essential Drugs Co. Ltd, Dhaka, Bangladesh, for their initiatives to provide the scope of research on this matter. Recognition also goes to Bangladesh Forest Industries Development Corporation (BFIDC) for their all support to implement this project and co operation during the process operation. 


\section{REFERENCES}

[1] B. K. Sharma, Industrial Chemistry, Goel Publisher House, India, p. 527.

[2] Data and Reports Provided by the Bangladesh Forest Industries Development Corporation (BFIDC).

[3] Data and Information Provided by Poly Era Chemicals, Malaysia.

[4] Project Report of Essential Latex Processing Plant (ELPP), Bangladesh, 2011, 2012.

[5] Data collected from Malaysian Rubber Board Authority, 2011, 2012.

[6] Erin T. Mcneil, Carolin E. Gilmore, William R. Finger, JoAnn S. Lewis and William P. Schelistede, The Latex Condom: Recent Advances, Future Directions.

[7] Randolph Norris Shreve, George T Austin, Shreves Chemical Process Industries, McGraw Hill, Fifth Edition.
[8] John Cecil and Peter Mitchell, "Processing of Natural Rubber", FAO 2003, available at: http://ecoport.org/ep?SearchType=earticleView \&earticleId $=187$ \&page $=2478$

[9] Sadhan K. De and Jim R.White, Rubber Technologist's Handbook, Vol 1, Rapra Technology Limited, 2001.

[10] Company Brochure of Thai Rubber latex Corporation (Thailand), Public Co. LTD, available at: http://www.thaitexgroup.com/thai2/main_page/ Thaitexgroup.html

[11] Web Article on "Latex Preservation and Concentration", available at: http://rubberboard.org.in/ManageCultivation.asp ?Id=192 